\title{
Article
}

\section{Delayed effects of a 20-min crushed ice application on knee joint position sense assessed by a functional task during a re- warming period}

Alexander, Jill, Richards, James, Attah, Obed, Cheema, Sameet, Snook, Joanna, Wisdell, Chloe, May, Karen Alison and Selfe, James

Available at http://clok.uclan.ac.uk/21854/

Alexander, Jill ORCID: 0000-0002-6492-1621, Richards, James ORCID: 00000002-4004-3115, Attah, Obed, Cheema, Sameet, Snook, Joanna, Wisdell, Chloe, May, Karen Alison ORCID: 0000-0001-9621-8466 and Selfe, James (2018) Delayed effects of a 20-min crushed ice application on knee joint position sense assessed by a functional task during a re-warming period. Gait \& Posture, 62 . pp. 173-178. ISSN 0966-6362

It is advisable to refer to the publisher's version if you intend to cite from the work. http://dx.doi.org/10.1016/j.gaitpost.2018.03.015

For more information about UCLan's research in this area go to http://www.uclan.ac.uk/researchgroups/ and search for <name of research Group>.

For information about Research generally at UCLan please go to http://www.uclan.ac.uk/research/

All outputs in CLoK are protected by Intellectual Property Rights law, including Copyright law. Copyright, IPR and Moral Rights for the works on this site are retained by the individual authors and/or other copyright owners. Terms and conditions for use of this material are defined in the policies page. 


\title{
Delayed effects of a 20-minute crushed ice application on knee joint position sense assessed by a functional task during a re-warming period.
}

Alexander J, Richards J, Attah O, Cheema S, Snook J, Wisdell C, May K, Selfe J.

\begin{abstract}
Introduction: The effect of cryotherapy on joint positioning presents conflicting debates as to whether individuals are at an increased risk of injury when returning to play following cryotherapy application at the lower limb.

Objectives: The aim of this study was to investigate whether a 20 minute application of crushed ice at the knee affects knee joint position sense immediately post and up to 20 mins post ice removal, assessed during a small knee bend. Method: 17 healthy male participants took part in the study performing a functional task. Using three-dimensional motion analysis (Qualisys Medical AB Gothenburg, Sweden), kinematics of the knee were measured during a weight bearing functional task pre and immediately post, 5, 10, 15 and 20 minutes post cryotherapy intervention. Skin surface temperature (Tsk) cooling was measured via infrared non-contact thermal imaging (Flir Systems, Danderyd, Sweden) over the anterior and medial aspect of the knee.

Results: Results demonstrated significant reductions in the ability to accurately replicate knee joint positioning. A significant increase $(P=>0.05)$ in rotational movement in the transverse plane occurred, 20 minutes post ice removal.

Discussion: A 20-minute application of crushed ice to the anterior aspect of the nondominant knee has an adverse effect on knee joint repositioning and dynamic stability, 20 minutes after ice is removed. In consideration of returning a land-based athlete to dynamic functional activities, post cryotherapeutic intervention at the knee, clinicians should consider these findings due to the potential increase risk of injury.
\end{abstract}

Keywords: Cryotherapy; knee; kinematics; joint position sense. 


\section{Introduction}

A common practice within clinical and sporting populations for acute injury management, cryotherapy is known to provide a multitude of physiological changes [1,2]. Reductions in oedema, nerve conduction velocity (NCV) [3], and tissue metabolism are reported $[4,5,6]$ in addition to changes in joint position sense (JPS) and proprioception [7,8]. It is known that athletes commonly return to field of play following cryotherapy applications of varying exposure durations at half-time, pitch-side or during competitive play [1]. Ultimately a therapeutic analgesic affect is intended following the application of cryotherapeutic modalities and is well reported throughout literature to support early injury management [2,9]. Negative effects of cold therapy report superficial skin burns [10] and reductions in muscle strength [1]. Tissue cooling modalities used include; frozen peas, cubed ice, crushed ice, wetted ice, cold water immersion, cold packs [11,12] and whole-body cryotherapy [13]. Consensus proposes that different therapeutic effects arise across cryotherapy modalities or exposures and therefore effects may not be equitable [9]. Current literature suggests that crushed ice is a favourable method of achieving the most efficient analgesic response $[11,14,15,16]$. Recent findings however suggest that wetted ice compared to crushed ice appears to be the optimum choice for cooling the skin surface [12]. Local analgesia has been confirmed at a skin surface temperature $\left(T_{s k}\right)$ of $13.6^{\circ} \mathrm{C}$ and reductions in $\mathrm{NCV}$ at $12.5^{\circ} \mathrm{C}[3,4]$, suggesting that a therapeutic range exists between $10-15^{\circ} \mathrm{C}$ [11]. To observe whether therapeutic range is achieved following cryotherapeutic application, non-invasive infrared thermal imaging cameras serve as an accurate method of quantifying $T_{s k}$ in sports medicine research $[2,15,17]$. In addition, a relationship has been shown between $T_{s k}$ and intramuscular temperature $\left(T_{i m}\right)$ cooling [18], where $T_{i m}$ continues to cool whilst $T_{s k}$ rewarms and therefore showing a delayed effect. This poses consideration of the effect on muscle spindle activity and changes in neuromuscular feedback, which may also be delayed. With athletes in contact sports commonly returning to the field of play following short cryotherapy applications for the treatment of pain $[1,7]$. Previous work proposes a potential risk of injury in athletes commonly returning to the field of play following short cryotherapy applications for the treatment of pain $[1,7]$, these include adverse adaptations occurring from potential physiological changes that may affect the knee joint [7]. However there is a lack of consensus in the literature as to the effect cryotherapy modalities on JPS, muscle strength and functional stability $[1,19]$. Awareness of joint position (joint position sense), movement and force, either consciously or unconsciously summarises clinically the term 'proprioception' [20, 21], which have direct implications to functional stability. A functional way of measuring proprioceptive acuity [22, 23], JPS is reported as the ability of a person to replicate a joint angle [24,25]. To observe functional movement appropriate to replicating land-based sports, weight bearing tasks are recommended $[26,27]$. To mimic functional performance in athletic populations, JPS may be 
assessed through active angle reproduction (AAR) $[22,24,28]$. Such proprioceptive deficits may expose athletes to reduced injury or re-injury risk, [29]. A reduction in accuracy of JPS in the sagittal plane and knee control in the coronal plane has been shown during the descent phase of a small knee bend (SKB) after the removal of crushed [7], which supports previous findings on JPS [29, 30,31]. Conflicting discussions as to the effects of cooling on JPS and joint stability exist and literature remains scarce as to the investigation into the longevity of such effects post cooling [30]. This study therefore aimed to explore the effect of crushed ice application at the knee, pre cooling and post cooling at 5-minute intervals up to 20 minutes on knee flexion AAR and knee joint stability. The purpose of this was to inform clinicians on appropriate local cooling protocols to reduce the risk of injury during competitive play or prior to returning to exercise.

\section{Methods}

\subsection{Ethics}

All participants provided written and verbal consent to take part in the study, and completed a Physical Activity Readiness Questionnaire (PAR-Q) prior to participation in the study. The study was conducted according to the Declaration of Helsinki [33] and approved by UCLan STEMH Ethics Committee.

\subsection{Participants}

The study was a single group, pre-test-post-test design. Forty potential participants were screened to participate in the study. Inclusion criteria included; aged between 18-40 years old, played competitive land-based sports regularly, were currently free from lower limb injury or with no history of lower limb injuries. Due to the differences in the effect of tissue cooling across genders an all-male sample was used to maintain homogeneity [34]. Exclusion criteria included; previous knee joint surgery, referred knee pain to or from the knee, contraindications to cryotherapy or lower limb injury in the previous 6 months [11]. Seventeen participants met the inclusion criteria aged $21.8 \pm 3.5$ years, height $177.9 \pm 7.9 \mathrm{Cm}$, mass $81.1 \pm 16.5 \mathrm{Kg}$, and BMI $25.6 \pm 2.8 \mathrm{~kg} / \mathrm{m}^{2}$.

\subsection{Procedures}

Data were collected in a movement analysis laboratory, in order to achieve a stable thermal state, participants acclimatised to the testing environment for 15 minutes $[10,11]$. Kinematic data were collected at $115 \mathrm{~Hz}$ using a 10 camera Oqus camera system and processed in Qualisys Track Manager (Qualisys Medical AB, Gothenburg, Sweden), data were then exported as C3D files and imported to Visual3D software (CMotion Inc., USA). $T_{s k}$ over the anterior aspect of the non-dominant knee was measured via a non-invasive infrared thermal 
imaging camera (ThermoVision A40M, Flir Systems, Danderyd, Sweden). In line with current medical standard protocols, emissivity of the thermal imaging camera was set at 0.97-0.98 $[35,36]$. Passive retro-reflective markers were applied to specific anatomical landmarks; anterior superior iliac spine (ASIS), posterior superior iliac spine (PSIS), greater trochanter, medial and lateral epicondyles of the femur, calcaneus, medial and lateral malleoli, head of first and fifth metatarsals, central cuneiform. Cluster markers were applied to the anterolateral aspect of the femur and tibia (Figure 1). Static kinematic images included; radial styloid, acromion process and lateral epicondyle of the humerus, these markers were then removed prior to the functional task.

Testing was carried out on the participant's non-dominant limb in support of earlier literature $[36,37,38]$. Previous literature suggests the non-dominant limb should be chosen in such tasks as it is commonly injured during sport compared to the contralateral limb and is commonly the weight-bearing limb during dynamic tasks on the field of play $[36,37,38]$. Participants were familiarised to the functional task of a SKB, whereby a practice attempt to replicate a $45^{\circ}$ knee movement pattern was completed, prior to testing [39], supporting similar methodology that suggested JPS observed at the knee should commence between angles of $40^{\circ}$ and $80^{\circ}$ knee flexion [40]. To ensure eco-validity of the study, no blindfolds or white noise were used during testing, as it was felt that this would reduce sensory cues and would not replicate normal sporting activity [7].

To begin, the participant lay in a semi recumbent position on a plinth, and pre-intervention $T_{s k}$ data were collected using a TI camera. Two ROIs were determined by the application of wooden markers applied to the apex and base of the patella. Five images were collected at baseline, immediately post cryotherapy removal, and at 5-minute intervals, up to 20 minutes' post cryotherapy removal. Following $T_{s k}$ baseline data, the participant was asked to stand centrally in the middle of the motion analysis cameras and perform five SKB for a baseline measure. Previous work suggests between 4-5 repetitions of a AAR allows for the stabilisation of data [22]. The target angle of $45^{\circ}$ was held for $5 s$ (Figure 2) supporting previous methodologies [2,7] and limb position awareness [8]. Participants were then removed from the motion analysis capture and taken back to the plinth via a wheelchair, and the anatomical markers on the medial and lateral epicondyles of the femur were removed. Replicating previous methodologies, a clear plastic bag containing $800 \mathrm{~g}$ of crushed ice $(\mathrm{Cl})$ was applied to the non-dominant knee over the anterior aspect for an exposure time of 20 minutes $[7,11]$ covered by a damp microfiber towel and held in place by cling film wrap. On immediate removal of the $\mathrm{Cl}$, five $\mathrm{TI}$ images were taken of the anterior and medial aspects of the knee and the two reflective markers were re-applied. Participants completed five SKB and then 
returned to the plinth for the remainder of 5 minutes. At 5-minute intervals this method was repeated, with five $T_{s k}$ images and five SKB completed, up to 20 -minutes post. The 20 -minute re-warming period included the time of each proprioceptive assessment at each of the 5minute time points.

\subsection{Statistical analysis}

Minimum and maximum knee joint ROM in all three planes for the entire SKB functional task were recorded. Prior to statistical analysis, the averaged value for each time point for each subject was found. A Shapiro-Wilk test reported that data were normally distributed and suitable for parametric testing. A repeated measures ANOVA with Least Significant Difference pairwise comparisons were used to compare differences between timepoints. Statistical significance level was set at $p=0.05$. Statistical analysis was conducted via SPSS (Version 22, SPSS, Inc. Chicago, USA).

\section{Results}

\subsection{Skin surface temperature}

ROI over the anterior aspect of the knee were subdivided into ROIA (patella) and ROIB (medial knee). The repeated measures ANOVA showed significant differences between ROIA and ROIB and between all time-points $\left(\mathrm{p}<0.001, \mathrm{p \eta}^{2}>0.88\right)$, Table 1. A further pairwise revealed significant differences between all time-points indicting rewarming is occurring in both ROls up to 20 minutes at which point is has not returned to the baseline temperature, Table 3 . Therapeutic range was met for ROIA $\left(14.6 \pm 2.2^{\circ} \mathrm{C}\right)$ immediately post cryotherapy removal but not for ROIB $\left(20.3 \pm 3.7^{\circ} \mathrm{C}\right)$ at any time point.

\subsection{Joint Kinematics}

The repeated measures ANOVA showed no significant differences in maximum and range of motion of the knee in the sagittal and coronal planes. However, a significant difference was seen in the transverse plane ROM $\left(p=0.016, p \eta^{2}=0.31\right)$, Table 2. Further post hoc analysis showed significant incremental differences between 20 minutes' post cryotherapy removal and all other time-points $(p=0.03$ to $p=0.004)$ with the greatest change between 20 minutes and pre-cooling, which showed a $25 \%$ increase in transverse plane ROM. No other significant differences were recorded between time points for transverse plane ROM, Table 3.

\subsection{Interaction between Joint Kinematics and Skin and Intramuscular Temperature}

The correlation between skin surface rewarming temperature over the two regions of interest ROIA and ROIB and transverse plane knee angle ROM were further explored using a Pearson 
correlation coefficient and found to be strongly positively corrected ( 0.82 and 0.83 ) respectively. In addition, the IM cooling was estimated from the equations from Hardaker et al. [18] who showed that as the surface skin temperature rewarms the IM continues to cool. Figure 3 shows that as the surface re-warms and the IM continues to cool the transverse plane knee angle ROM, or knee instability increases.

\section{Discussion}

Over a 20-minute re-warming period following cryotherapy intervention at the knee, it was unknown as to whether delayed effects occur in relation to joint stability, neuromuscular adaptations and JPS. This may be clinically important as in many land-based sports, athletes return to either functional activities or the field of play following cryotherapy exposures via breaks in play, or rolling substitutions with a potential increase in susceptibility for injury proposed from the present findings.

The current study reports significant changes in the rotational range in the transverse plane at 20 minutes' post cryotherapy removal during a SKB $(p<0.05)$. The current study reports significant changes in the rotational range in the transverse plane at 20 minutes' post cryotherapy removal during a SKB $(p<0.05)$. Although the magnitude of this difference could be considered small (1.3 degrees), this represents a $25 \%$ increase. This is similar in magnitude to the findings reported by Selfe et al [41] when considering improvements in stability with a bracing intervention, albeit a reduction in transverse plane range of movement in this case.

Significant differences between time-point during rewarming were reported over the patella and medial aspect of the knee, with the patella reaching the therapeutic range for an analgesic response immediately post crushed ice removal $[1,11]$. $T_{s k}$ did not return to baseline in either $\mathrm{ROI}$ at 20-minutes post intervention removal, which are in agreement with the findings of Kennet et al [11] who studied a 30-minute rewarming period with a variety of cooling modalities. The medial aspect of the knee (ROIB) however did not reach therapeutic range $\left(20.3 \pm 3.6^{\circ} \mathrm{C}\right)$. Although it is suggested that the application area and modality of cryotherapy applied may have influenced this result as $\mathrm{Cl}$ was applied directly over the anterior aspect of the knee rather than the medial or lateral regions. This may explain the non-significant results immediately post $\mathrm{Cl}$ removal throughout all ROM. If cooling was directly applied to medial and lateral aspects of the knee immediate changes in ROM might have occurred, due to reduction in afferent information provided by muscle spindles in soft tissue structures surrounding the knee, which supports similar effects reported by Alexander et al [7]. The application of pitchside cryotherapy however in acute injury management is often applied for less than 10 minutes, and is not always packed around the entire knee joint, so further investigation is 
required to explore the range of common pitch-side practice. In addition, although $\mathrm{Cl}$ is the cryotherapy modality supported in the literature [11], wetted ice may have produced a deeper and consistent cooling effect compared to $\mathrm{Cl}$ [12].

At 20-minutes post cryotherapy intervention, participants were able to replicate the target angle of $45^{\circ}$, however a significant increase in the knee range of motion in the transverse plane at 20 minutes post cooling compared to all other time points. Conduction and convection has been shown to influence the cooling mechanisms of superficial and deeper soft tissues [14]. Previous work showed significant negative quadratic relationship between $T_{s k}$ and $T_{i m}$ [18], with intramuscular cooling continuing after the removal of an ice pack. We postulate that this mechanism could have a physiological influence on neuromuscular response 20-minutes post intervention. This is contrary to previously research, which has suggested that deeper regions of the sensorimotor system within a joint are not affected by the application of cryotherapy [42]. In addition, Wassinger et al [41] assumed that deeper mechanoreceptors were able to compensate for receptors affected by cryotherapy at a superficial level.

The current study proposes that deeper sensorimotor mechanisms may be affected through the delayed $T_{i m}$ response over a're-warming' period, which could affect proprioceptive feedback and motor control. A concept which is supported by Uchio et al [30], who reported a decrease in NCV and altered proprioceptive feedback caused by cryotherapy intervention. Therefore, as $T_{s k}$ re-warms Hardaker et al [18] suggested that $T_{i m}$ continues to cool and affecting the proprioceptive mechanisms and in turn control at the knee due to delayed intramuscular and ligamentous cooling. However to date literature has not reported the effects of re-warming on joint control and stability. This is particularly pertinent, as a decrease in rotational stability at the knee, as seen in this study, is a known injury mechanism at the knee, therefore it may be suggested there is a risk of injury at 20 minutes' post cryotherapy removal through altered mechanoreceptor feedback resulting in reduced proprioceptive control.

In consideration of the known $\mathrm{T}_{s k}$ and $\mathrm{T}_{\text {im }}$ relationship suggested in previous literature [18], the current study proposes that a relationship exists between skin temperature, intra muscular temperature and transverse plane knee stability over a re-warming period of 20 minutes. Representative in figure 2, post cryotherapy removal, time-points for $T_{s k}$ and transverse ROM were combined with $\mathrm{T}_{\text {im }}$ data presented by Hardaker et al [18] and compared to baseline pre cooled values. The delayed deeper tissue cooling could affect the function of muscle spindle firing via responsive afferent and efferent signals [42]. Another explanation for the increase in the transverse plane knee ROM at 20 minutes post cooling, may be due to the continued cooling effect on the muscular tissues structures surrounding the joint inducing a stiffening response around the joint producing a compensatory mechanism. 
The implications of this study has a confounding impact on not only the management of pitchside cryotherapy application but also the application for use in facilitating joint movement during rehabilitation. The consideration of a controlled re-warming period prior to any closedchain functional movement of the lower limb after icing the knee is important. This may reduce the chance of injury risk, specifically considering movement patterns for non-contact ACL injury, by returning to functional activities within this 20-minute window, post cryotherapy application which has yet to be addressed within the literature. Future considerations into observation of longer re-warming periods may be of interest to observe the return of baseline ROM following local joint cooling.

Limitations

In this study we chose to conduct the assessment without blindfolding the participants as this would represent how the small knee bend would be performed in clinical practice or normal sporting activities, however allowing visual input may have influenced the assessment of proprioception. Future research should consider removal of visual cues to ensure changes observed were due to proprioceptive deficits as visual feedback may have mitigated potential changes reported here. In addition, we chose to move the participants into position using a wheelchair to minimise activity and hence standardise between participants, therefore these results should be taken in context of minimal muscle activity which would influence rewarming. Another limitation to this study is the lack of control group to ensure no learning effect has taken place. The monitoring of longer rewarming periods should be considered to investigate at what point joint control returns to baseline measures.

\section{Conclusion}

A 20-minute exposure of crushed ice to the anterior aspect of the non-dominant knee presented adverse effect on dynamic stability, post 20 minutes following ice removal. This may be due to delayed neuromuscular responses in deeper tissues affecting sensorimotor mechanisms and mechanoreceptor feedback through reduced proprioceptive control. When returning to dynamic functional activities, post cryotherapeutic intervention, clinicians should consider these findings with the view of potential increase risk of injury.

\section{Conflict of interest statement}

We can confirm that there is no conflict of interests for any of the authors.

\section{References}


[1] Bleakley C, Costello JT, Glasgow PD. Should athletes return to sport after applying ice. A systematic review of the effect of local cooling on functional performance. Sports Med, 42 (2012) 69-87.

[2] Costello JT, Algar, LA and Donnelly AE. Effects of whole-body cryotherapy $\left(-110^{\circ} \mathrm{C}\right)$ on proprioception and indices of muscle damage. Scand J Med Sci Sport, 22 (2012) 190-198.

[3] Jutte LS, Merrick MA, Ingersoll CD, Edwards JE. The relationship between intramuscular temperature, skin temperature, and adipose thickness during cryotherapy and rewarming. Arch Phys Med Rehabil. 822001 845-850.

[4] Bugaj R. The cooling, analgesic, and rewarming effects of ice massage on localized skin. Phys Ther. 55 (1975) 11-19.

[5] K, Knight, and D, Draper, Therapeutic Modalities. The art and science, Second ed., Baltimore: Lippincott Williams and Wilkins, 2013.

[6] Topp, R., Ledford, E., Jacks, D. Topical Menthol, Ice, Peripheral Blood Flow and Perceived Discomfort. J Athl Train. 48 (2013) 220-225.

[7] Alexander, J, Selfe, J, Oliver, B, Mee, D, Carter, A, Scott, M, Richards, J, May, K. An exploratory study into the effects of a 20 minute crushed ice application on knee joint position sense during a small knee bend. Phys Ther Sp. 18 (2016) 21-26.

[8] Costello JT and Donnelly AE. Cryotherapy and joint position sense in healthy participants: A systematic review. J Athl Train, 45 (2010) 306-316.

[9] Bleakley C, Glasgow, P, Phillps, N, Hanna, L, Callaghan, M, Davison, G, Hopkins, T and Delahunt, E. Management of acute soft tissue injury using protection, rest, ice, compression and elevation recommendations from the Association of Chartered Physiotherapists in Sports and Exercise Medicine (ACPSM). Physio's in Sport, 1 (2011) $1-22$.

[10] Selfe, J, Hardaker, N, Whitaker, J, and Hayes, C. Thermal Imaging of an Ice Burn Over the Patella Following Clinically Relevant Cryotherapy Application During a Clinical Research Study. Phys Ther Sport. 8 (2007) 153-158.

[11] Kennett, J, Hardaker, N, Hobbs, S and Selfe J. Cooling efficiency of 4 common cryotherapeutic agents. J Athl Train, 42 (2007) 343-348. 
[12] Dykstra, J, Hill, H, Miller, M, Cheatham, C, Michael, T, and Baker, R. Comparisons of cubed ice, crushed ice, and wetted ice on intramuscular and surface temperature changes. J Athl Train, 44 (2009) 136-141.

[13] Selfe, J., Alexander, J, Costello, J, May, K, Garratt, N, Atkins, S, Dillon, S, Hurst H, Davison, M, Przybyla, D, Coley, A, Bitcon, M, Littler, G and Richards, G. The effect of three different $\left(-135^{\circ} \mathrm{C}\right)$ whole body cryotherapy exposure durations on elite rugby league players. Plos One, 9 (2014) 1-9.

[14] Hardy M, and Woodall, W. Therapeutic effects of Heat, Cold, and Stretch and Connective Tissue. J Hand Ther. 11 (1998) 148-156.

[15] Merrick, M., Jutte, L and Smith, M. Cold modalities with different thermodynamic properties produce different surface and intramuscular temperatures. J Athl Train. 38 (2003) 28-33.

[16] Kanlayanaphotporn, R., and Janwantanakul, P. Comparison of skin surface temperature during the application of various cryotherapy modalities. Arch Phys Med, Rehab. 86 (2005) 1411-1415.

[17] Costello, J., Stewart, I., Selfe, J., Karki, A., Donnelly, A. Use of thermal imaging in sports medicine research: A short report. Int. Sport Med J. 14 (2013) 94-98.

[18] Hardaker, N, Moss, A, Richards, Jarvis, S, McEwan, I and Selfe, J. The relationship between skin surface temperatures measured via Non-Contact Thermal Imaging and intramuscular temperature of the rectus femoris muscle. Ther Int. 17 (2007) 45-50.

[19] Bleakley, C. and Costello, J. Do Thermal Agents Affect Range of Movement and Mechanical Properties in Soft Tissues? A Systematic Review. Arch Phys Med Rehab. 94 (2013).149-163.

[20] Röijezon U, Clark NC, Treleaven J. Proprioception in musculoskeletal rehabilitation. Part 1: Basic science and principles of assessment and clinical interventions. Man Ther. 3 (2015). 368-77.

[21] Butler AA, Héroux ME, Gandevia SC. Body ownership and a new proprioceptive role for muscle spindles. Acta Physiol (Oxf). 1 (2017). 19-27. 
[22] Selfe J, Callaghan, M, McHenry, A, Richards, J and Oldham, J. An investigation into the effect of number of trials during proprioceptive testing in patients with patellofemoral pain syndrome. J Orthop Res, 24 (2006) 1218-24.

[23] Costello JT and Donnelly AE. Effects of cold water immersion on knee joint position sense in healthy volunteers. J Sports Sci. 2011, 29, 449-456.

[24] Bennell K, Wee E, Crossley K, Stillman B, Hodges P. Effects of experimentallyinduced anterior knee pain on knee joint position sense in healthy individuals. J Orthop Res. 23 (2005) 46-53.

[25] Ribeiro F, Mota J, Oliveira J. Effect of exercise-induced fatigue on position sense of the knee in the elderly. Eur J Appl Physiol. 99 (2007) 379-385.

[26] Drouin, J, Houglum, P, Perrin, D, Gansneder, B. Weight-bearing and Non-WeightBearing Knee-Joint Reposition Sense and Functional Performance, J Sport Rehabil.12 (2003) 54-66.

[27] Herrington, L. Knee-Joint position sense: The relationship between open and closed kinetic chain tests. J Sport Rehabil. 14 (2005) 356-362.

[28] Stillman, B. Making sense of proprioception. Physio. 88 (2002) 667-676.

[29] Fullam, K., Caulfield, B., Caughlan, G.F., Delahunt, E. (2014). The effect of cryotherapy application to the ankle on dynamic stability in an athletic population. British Journal of Sports Medicine, 48(7), 596-674.

[30] Ribeiro F., Moreira, S., Neto, J., Oliveira J. Is the deleterious effect of cryotherapy on proprioception mitigated by exercise? Int. J Sports Med. 34 (2013) 444-448.

[31] Surenkok O, Aytar A, Tuzun EH, Akman MN. Cryotherapy impairs knee joint position sense and balance. Isokinet Exerc Sci. 16 (2008) 69-73.

[32] Uchio, Y, Ochi, M, Fujihara, A, Adachi N, Iwasa, J and Sakai, Y. Cryotherapy Influences Joint Laxity and Position Sense of the Healthy Knee Joint. Arch Phys Med Rehab. 84 (2003) 131-135.

[33] World Medical Association. Declaration of Helsinki. http://www.wma.net/e/ethicsunit/helsinki.htm 2013 (accessed 20.02.16). 
[34] Canker, K and Finderle Z. Gender differences in cutaneous vascular and autonomic nervous response to local cooling. Clin Autonomic Res. 13 (2003) 214-220.[38] Ring EFJ and Ammer K. The technique of infra-red imaging in medicine. Therm Int. 10 (2000) 7-14. [35] Selfe, J, Hardaker, N, Thewlis, D, and Karki, A. An Accurate and Reliable Method of Thermal Data Analysis in Thermal Imaging of the Anterior Knee for Use in Cryotherapy Research. Arch Phys Med Rehab. 87 (2006) 1630-1635.

[36] Vauhnik, R, Morrissey, M, Rutherford, O, Turk, Z, Pilih, I, and Pohar, M. Knee anterior laxity: a risk factor for traumatic knee injury among sports women? The Knee. 16 (2008) 823-833.

[37] Krajnc, Z, Vogrin, M, Recnik, G, Crnjac, A, Drobnic, M and Antolic, V. Increased risk of knee injuries and osteoarthritis in the non-dominant leg of former professional football players. Middle Eur J Med. 122 (2010) 40-43.

[38] Ruedl, G, Webhofer, M, Helle, K, Strobl, K, Shranz, A, Fink, C, Gatterer, H, and Burtscher, M. Leg Dominance is a Risk Factor for Non-Contact Anterior Cruciate Ligament Injuries in Female Recreational Skiers. Am J Sports Med. 40 (2012) 1269-1273.

[39] Reurink, G, Goudswaard, G, Oomen, H, Moen, M, Tol, J, Verhaar, J, and Weir, A. Reliability of the active and passive knee extension test in acute hamstring injuries. Am J Sports Med. 41 (2013) 1757-61.

[40] Olsson, LH, Lund, M, Henrikson, H, Rogind, H, Biddal and Danneskoid-Samsoe, B. Test-retest reliability of a knee joint position sense measurement in sitting and prone position. Adv Physio. 6 (2004) 37-47. [42] Khanmohammadi, R, Someh, M, and Ghafarinejad, F. The effect of cryotherapy on the normal ankle joint position sense. Asian J Sports Med. 2 (2011) 91-98.

[41] Selfe J, Richards J, Thewlis D, Kilmurray S. A clinical study of the biomechanics of step descent using different treatment modalities for patellofemoral pain. Gait Posture. 27 (2008) 258-63.

[42] Wassinger, C, Myers, J, Gatti, J. Proprioception and throwing accuracy in the dominant shoulder after cryotherapy. J Athl Train. 42 (2007) 84-89. 
[43] Proske, $U$ and Gandevia, S. (2012). The proprioceptive senses: their roles in signalling body shape, body position and movement, and muscle force. Physiol Rev. 92 (2012)16511697. 
Table 1: Descriptive statistics of the regions of interest rewarming and main effect of the repeated measures ANOVA between regions and across time points.

\begin{tabular}{lcccc}
\hline \multicolumn{1}{c}{ Time points } & $\begin{array}{c}\text { Mean (sd) } \\
\text { Patella temp }\end{array}$ & $\begin{array}{c}\text { Mean (sd) } \\
\text { Medial temp }\end{array}$ & P-value between regions & Effect size \\
\hline Pre-intervention & $28.7(1.2)$ & $29.4(1.2)$ & \\
0 minutes & $14.6(2.2)$ & $20.3(3.7)$ & \\
5 minutes & $19.7(1.7)$ & $23.5(2.3)$ & $<0.001$ & \\
10 minutes & $21.7(1.5)$ & $25.2(2.1)$ & \\
15 minutes & $23.1(1.4)$ & $26.0(1.5)$ & \\
20 minutes & $24.2(1.5)$ & $26.8(1.4)$ & \\
P-value between time points & \multicolumn{2}{c}{0.001} \\
effect size $\left(\mathrm{p \eta}^{2}\right)$ & \multicolumn{2}{c}{0.98} \\
\hline
\end{tabular}

Table 2: Descriptive statistics of kinematics and main effect of the repeated measures ANOVA across time points.

\begin{tabular}{lcccc}
\hline \multicolumn{1}{c}{ Time points } & $\begin{array}{c}\text { Mean (sd) } \\
\text { Maximum Knee } \\
\text { Flexion }\end{array}$ & $\begin{array}{c}\text { Mean (sd) } \\
\text { ROM Knee } \\
\text { Flexion }\end{array}$ & $\begin{array}{c}\text { Mean (sd) } \\
\text { Knee ROM } \\
\text { Coronal plane }\end{array}$ & $\begin{array}{c}\text { Mean (sd) } \\
\text { Knee ROM } \\
\text { Transverse plane }\end{array}$ \\
\hline Pre-intervention & $55.6(8.2)$ & $43.0(12.0)$ & $5.6(1.7)$ & $5.2(2.1)$ \\
0 minutes & $54.8(8.3)$ & $40.7(10.4)$ & $5.2(1.9)$ & $5.3(2.3)$ \\
5 minutes & $56.0(9.2)$ & $41.6(10.9)$ & $5.4(2.0)$ & $5.5(2.4)$ \\
10 minutes & $55.9(9.3)$ & $44.6(11.0)$ & $5.3(1.7)$ & $5.7(2.7)$ \\
15 minutes & $56.5(8.8)$ & $43.9(9.8)$ & $5.4(2.1)$ & $5.8(2.7)$ \\
20 minutes & $57.2(9.0)$ & $43.7(10.9)$ & $5.1(2.2)$ & $6.5(2.6)$ \\
\hline p-value & 0.186 & 0.235 & 0.825 & 0.016 \\
effect size $\left(\mathrm{p \eta}^{2}\right)$ & 0.098 & 0.086 & 0.026 & 0.31 \\
\hline
\end{tabular}

Table 3: Pairwise comparison between the time points for Knee ROM Transverse plane kinematics and regions of interest rewarming (* significant difference).

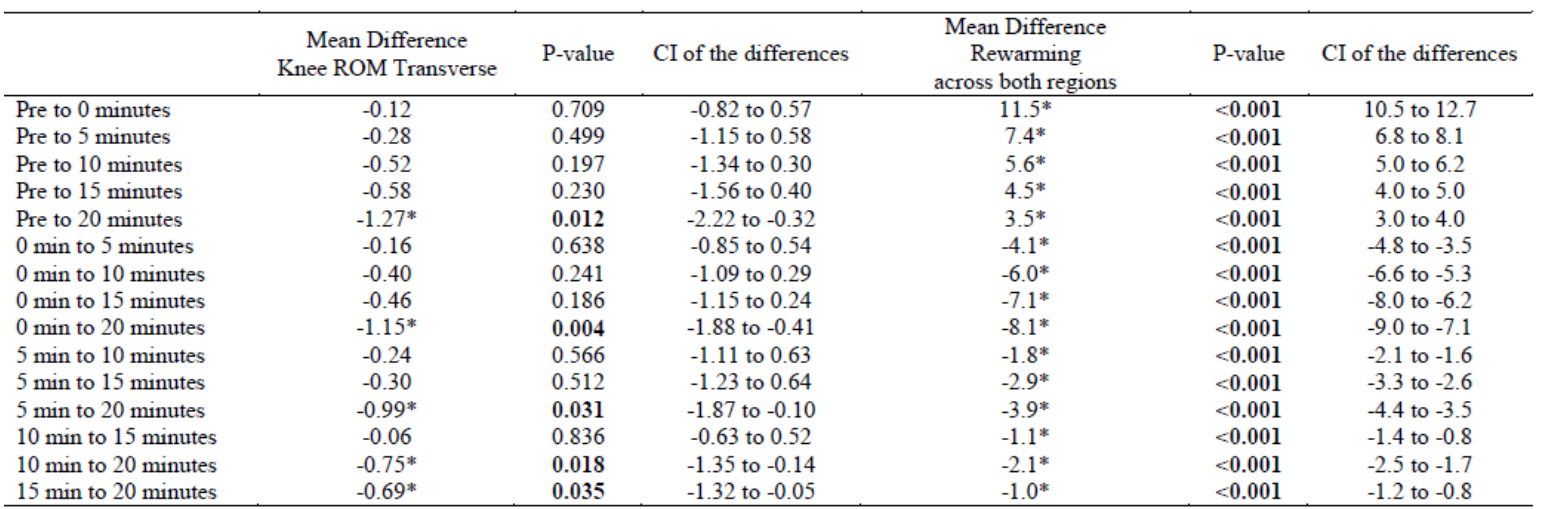




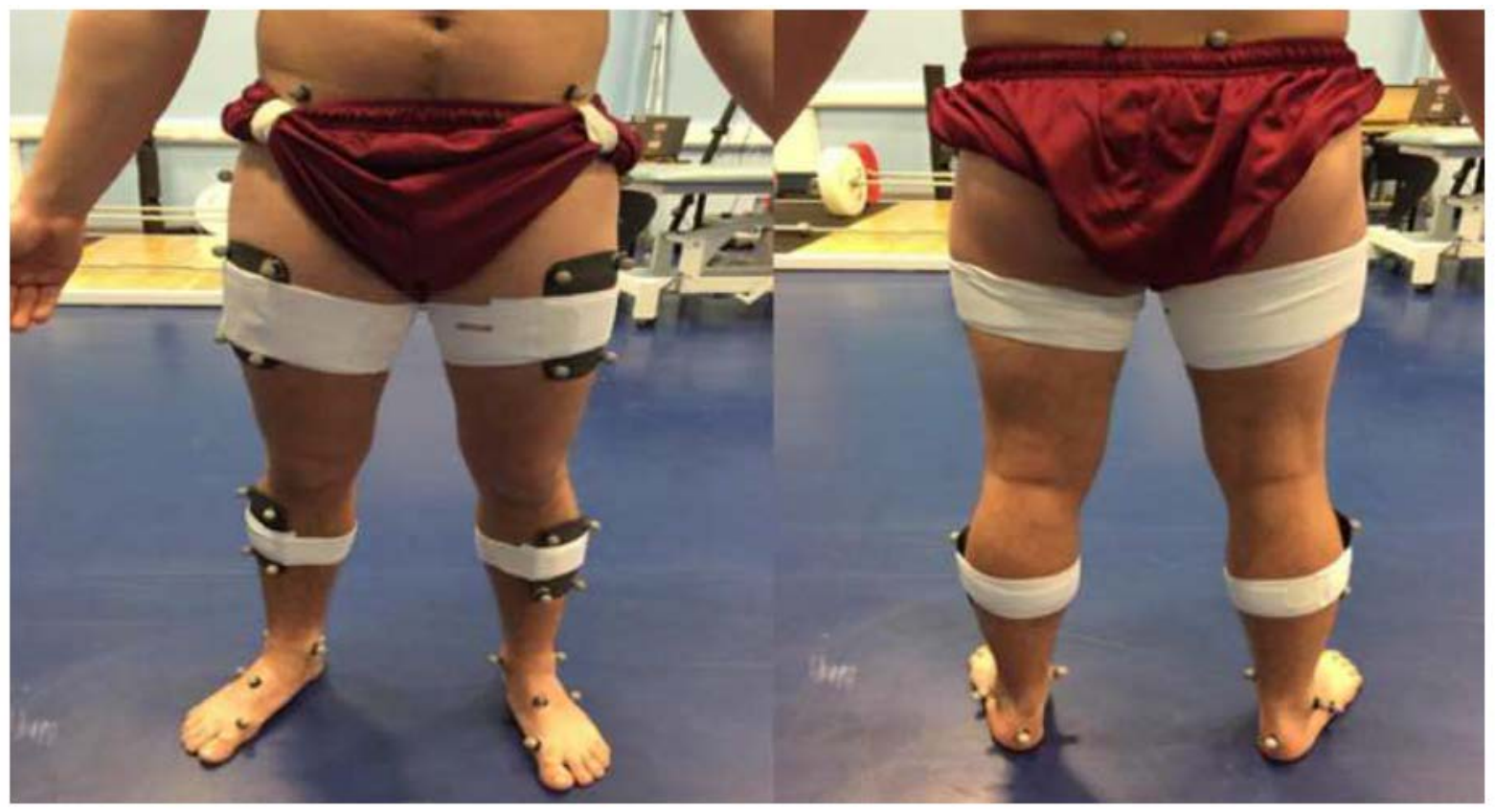

Figure 1 


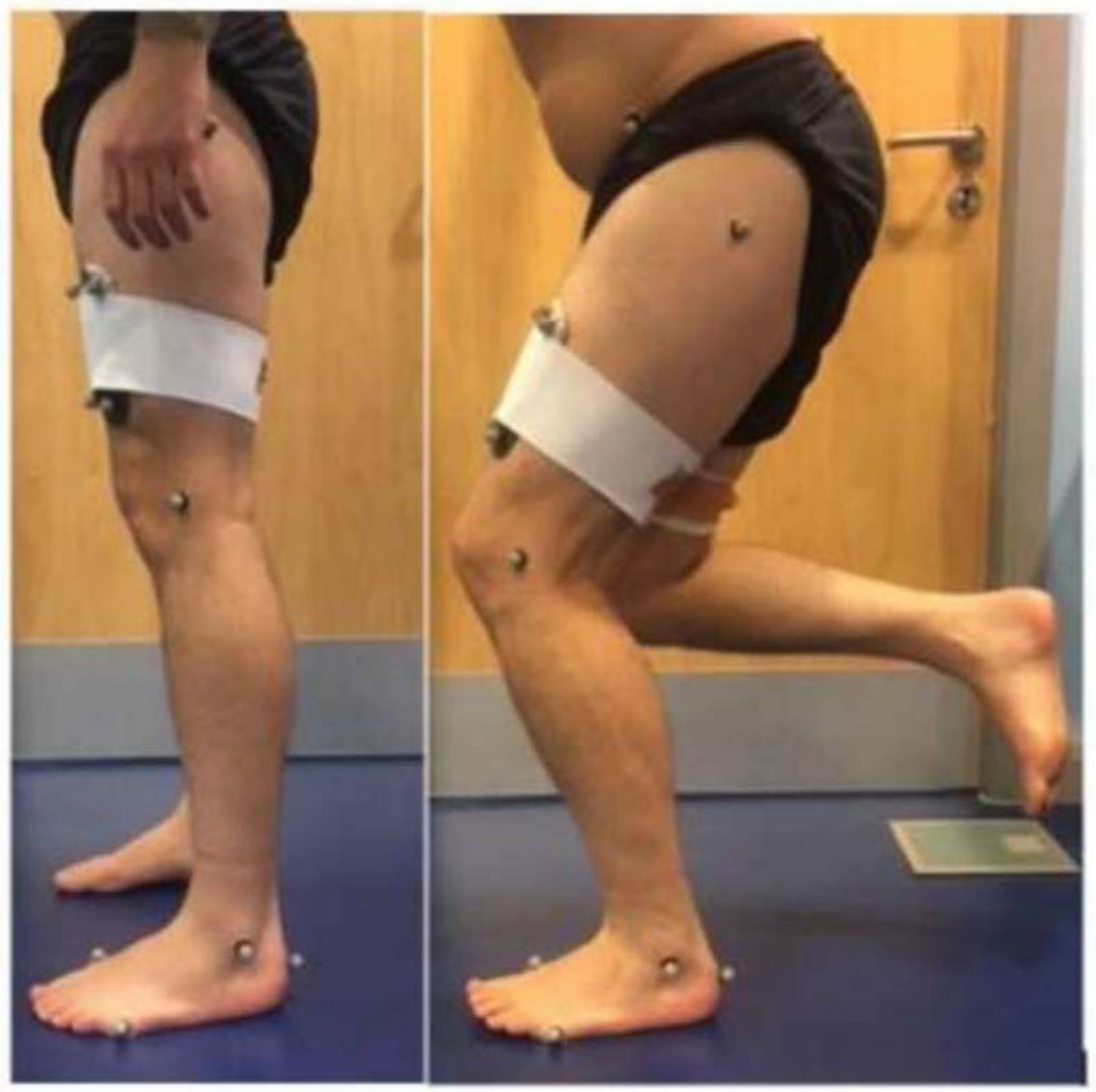

Figure 2 


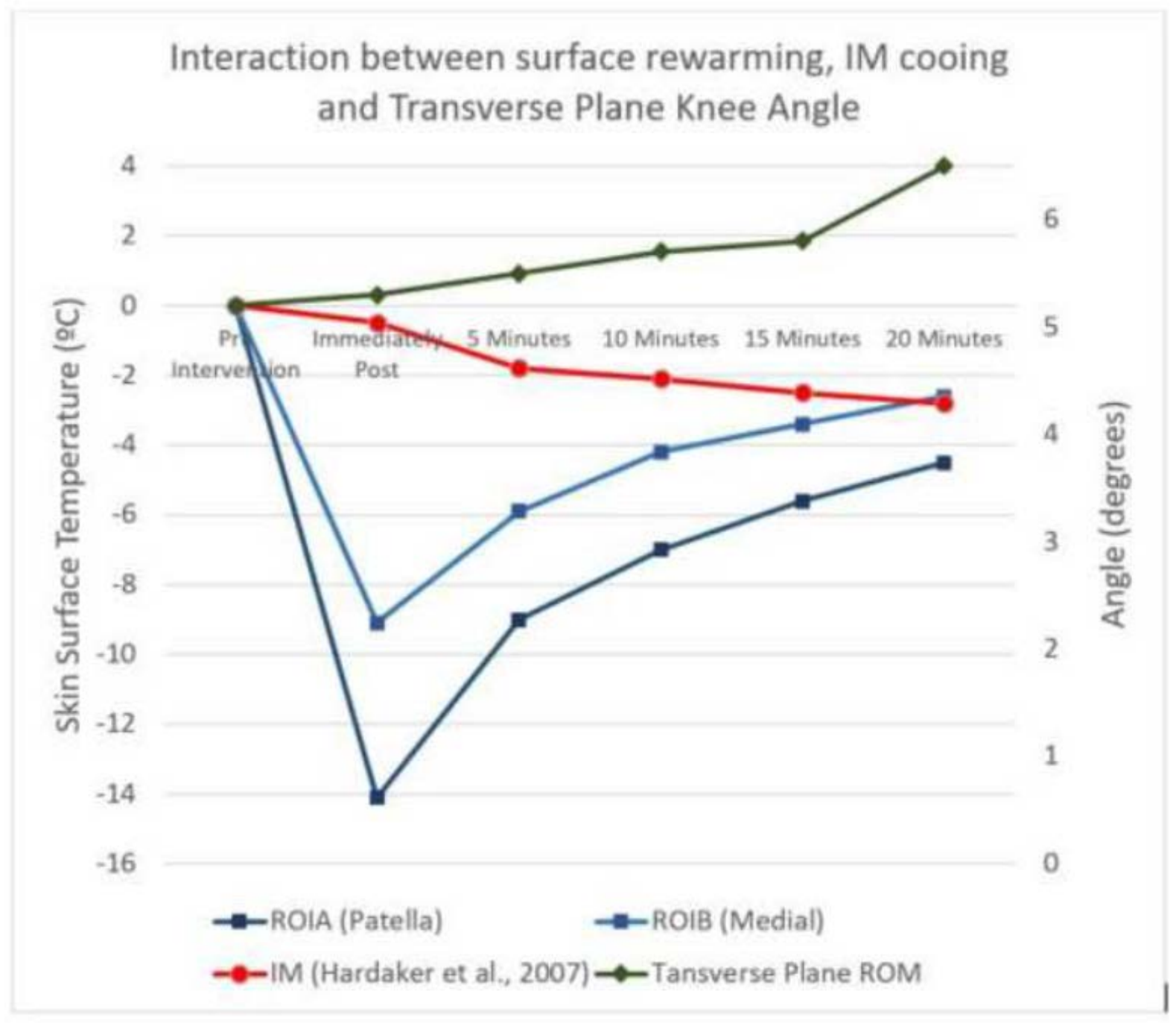

Figure 3 